\title{
Simulation of Structure, Intensity and Track of Super Cyclone Amphan Using High Resolution WRF-ARW Model
}

\author{
M. M. A. Sarker, D. A. Quadir, T. Rashid, M. N. Ahasan, S. D. Shuvo, J. Meandad, K. M. G. Rabbani \\ and T. R. Fariha
}

Department of Meteorology, Faculty of Earth and Environmental Sciences, University of Dhaka, Dhaka 1000, Bangladesh

Manuscript received: 21 September 2020: accepted for publication: 20 January 2021

\begin{abstract}
Studying the structure, intensity and track of tropical cyclone is very important in effective tropical cyclone warning. In this study, an attempt has been made to simulate the Super Cyclone Amphan to reproduce the structure, intensity and track of the storm that occurred over the Bay of Bengal and made landfall over the coastal zone of Sundarban between Western Bangladesh and Eastern West Bengal of India on 20 May 2020. The Weather Research and Forecasting (WRF) Model was run 120 hours from 0000 UTC of 16 May to 0000 UTC of 21 May 2021 with $9 \mathrm{~km}$ horizontal resolution to simulate the selected storm. The model simulated intensity and track of the storm were compared with that of best track data of India Meteorological Department (IMD). The results obtained from the WRF model indicated that the intensity of the selected cyclone in terms of Mean Sea Level Pressure (MSLP) and Maximum Sustained Wind speed (MSW) were $905 \mathrm{hPa}$ and $243 \mathrm{kph}$ whereas the observed MSLP and MSW were close to 920 $\mathrm{hPa}$ and $241 \mathrm{kph}$ respectively. It was also indicated that the model predicted the track of the cyclone reasonably well and it was quite close to the best track data throughout its path till landfall with very small deviation and the cyclone made landfall at 7-8 hours before the actual landfall with $167.4 \mathrm{~km}$ position error.
\end{abstract}

Keywords: Super cyclone, WRF model, Amphan, Track, Intensity

\section{INTRODUCTION}

The most destructive meteorological phenomenon of the warm tropical ocean is the tropical cyclone which ravages life and property especially over the coastal belt due to extreme landfall, strong wind, and associated storm surges at the time of landfall.

The mortality associated with the tropical cyclone is considerably high especially in the coastal zone of Bangladesh mainly due to poor socio-economic conditions of the people residing over that region. The Bay of Bengal is one of the most active zones of the world oceans for tropical cyclogenesis.

On an average, 80 tropical cyclones with wind speed equal to or greater than $62 \mathrm{~km} / \mathrm{hr}$ formed in the world ocean each year and $6.5 \%$ of the total tropical cyclones formed in the North Indian Ocean, of which $5.5 \%$ in the Bay of Bengal and 1\% in the Arabian Sea (McBride, 1995; Neumann, 1993).

The Advance Research WRF (ARW) dynamic core of the Weather Research and Forecasting (WRF) model (WRF-ARW) is being widely used for the simulation and prediction of extreme weather events

Corresponding author: T. Rashid

E-mail: towhidarashid@yahoo.com

DOI: https://doi.org/10.3329/dujees.v8i2.54835 including tropical cyclones over this region and globally (Routray et al. 2010; Osuri et al., 2012). A good number of articles are reported on the simulation and prediction of tropical cyclones over the North Indian Ocean (Mohanty et. al. 2004, 2010; Osuri et al. 2011, 2012, 2014; Rao and Prasad, 2006; Srinvas et al. 2010). It is well known that the characteristics of the tropical cyclone changes significantly at different stages of the life cycle. Though the track and intensity forecast of tropical cyclone has significantly improved (Mohapatra et. al., 2013a, 2013b and 2015), but still there is scope for further improvement in the structure, track and intensity forecast of tropical cyclones.

The main objective of the study is to simulate the structure, intensity and track of Super Cyclone $(\mathrm{SuC})$ Amphan using a high resolution WRF model. The secondary objective is to study the synoptic features associated with the selected case of SuC Amphan to improve the general understanding.

A study has undertaken to simulate the structure, intensity and track of SuC Amphan beginning from genesis to dissipation using WRF-ARW model. Section 1 describes the introduction of the study. A brief description of the selected SuC Amphan is given in section 2, detail of the model configuration, data used and methodology to carry out the study are discussed in section 3 . The results and discussion are presented in section 4 . 


\section{DESCRIPTION OF SUC AMPHAN}

Amphan was a powerful and deadly tropical cyclone formed over Bay of Bengal in 2020 that caused widespread damage in Bangladesh and West Bengal of India. A low-pressure area was developed with associated cyclonic circulation over the Southeast Bay of Bengal and adjoining South Andaman Sea on 13 May 2020. This low-pressure area was concentrated into a depression over central parts of South Bay of Bengal on 15 May 2020. The system was intensified into a cyclonic storm named Amphan on 16 May 2020 and continued to intensity. It intensified into a very severe cyclonic storm on 17 May 2020. The storm had developed an eye and started to intensify rapidly becoming an extremely severe cyclonic storm within 12 hours. As per the report of Joint Typhoon Warning (JTWC), it rapidly intensified from a Category 1 equivalent to Category 4 equivalent cyclone in just 6 hours. The Amphan upgraded to category 5 equivalent cyclones and recorded lowest central pressure was of $920 \mathrm{hPa}$ at approximately 12:00 UTC of 18 May 2020. At the same time, its position was over the west central Bay and adjoining areas and moved towards northwards.

From 19 May 2020 00:00 UTC the intensity of the tropical cyclone began to decrease and on 20 May 2020 at around 10:00 UTC the tropical cyclone began to hit the coast when the maximum sustainable wind speed was around about $155 \mathrm{kph}$ and $180 \mathrm{kph}$ with gust. The cyclone made landfall with its centre in eastern part of West Bengal (India) and Western Bangladesh in between 10:00 to 11:00 UTC of 20 May 2020. At the time of landfall, 1-min sustained winds estimated by JTWC was $155 \mathrm{kmph}$. The centre of the system was initially in West Bengal, then the system moved northward with its centre bent towards east, when it crossed Bangladesh border near Jhenaidah District and adjoining area between 15:00 to 16:00 UTC on the same day. It moved further northward and weakened into a land deep depression over the Rajshahi Division on the following morning (21 May 2020).

\section{MODEL DESCRIPTION, DATA USED AND METHODOLOGY}

\section{Model Description}

The National Centre for Atmospheric Research (NCAR) developed the Weather Research and
Forecasting (WRF) model in collaboration with the National Oceanic and Atmospheric Administration (NOAA), the National Centre for Environmental Prediction (NCEP) and various universities. Model equations, physics, and dynamics are described in detail by Skamarock et al. (2008). The WRF model version 4.1 with a single domain at $9 \mathrm{~km}$ horizontal resolution (Figure 1) and 40 vertical levels is used in this study. The Runge-Kutta 3rd order and terrainfollowing hydrostatic pressure for vertical coordinates time integration method was used. The physics options used are WSM 6-class microphysics scheme (Hong and Lim, 2006); Yonsei University planetary boundary layer scheme (Hong et al., 2006); KainFritsch cumulus scheme, (Kain and Fritsch, 1993). The Rapid Radiative Transfer Model (Mlawer et al., 1997) and Dudhia's scheme (Dudhia, 1989) are used for longwave radiation and shortwave radiation, respectively.

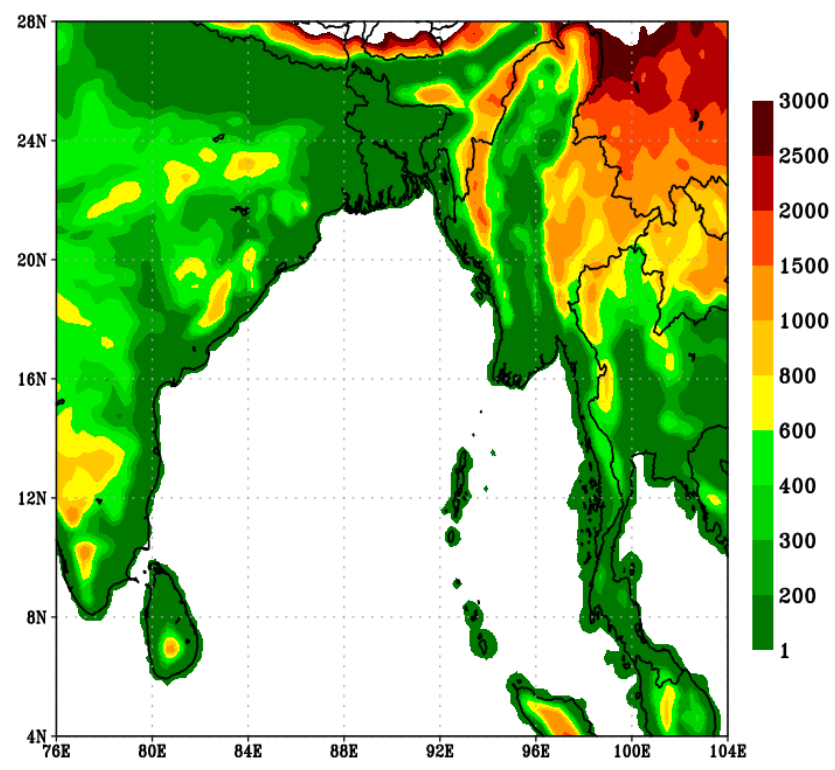

Figure 1: Model Domain used in WRF for Cyclone Simulation with $9 \mathrm{~km}$ Resolution. The Shading gives the Terrain Height in Meters

\section{Data Used}

The initial and boundary condition is the Global Forecast System (GFS) model data of $0.25^{\circ} \times 0.25^{\circ}$ horizontal resolution at six hourly intervals obtained from the National Center for Environmental Prediction (NCEP, USA). Best track information of tropical cyclone Amphan was taken from India Meteorology Department (IMD) (http://www. rsmcnewdelhi.imd.gov.in/). 


\section{Methodology}

The WRF model version 4.1 with a single domain at $9 \mathrm{~km}$ horizontal resolution is used in this study. The model is run using the initial conditions at 0000 UTC of 16 May 2021 for 120 hours (from 0000 UTC 16 May to 0000 UTC 21 May 2021) to obtain the forecasts tracks and landfall position of SuC Amphan. Model simulated and some derived meteorological parameters like surface wind, vertical profile of temperature and relative humidity, precipitation pattern, low level vorticity are investigated to study the structure and intensity. In addition, prediction of landfall time and location of $\mathrm{SuC}$ are also investigated.

Mean Error and Standard Deviation of position error are calculated to understand the accuracy of the model track.

\section{RESULTS AND DISCUSSION}

\section{Surface Wind Field}

Wind is one of the important features associated with a cyclone and accurate forecasting of wind help to minimize the damage to lives and properties.

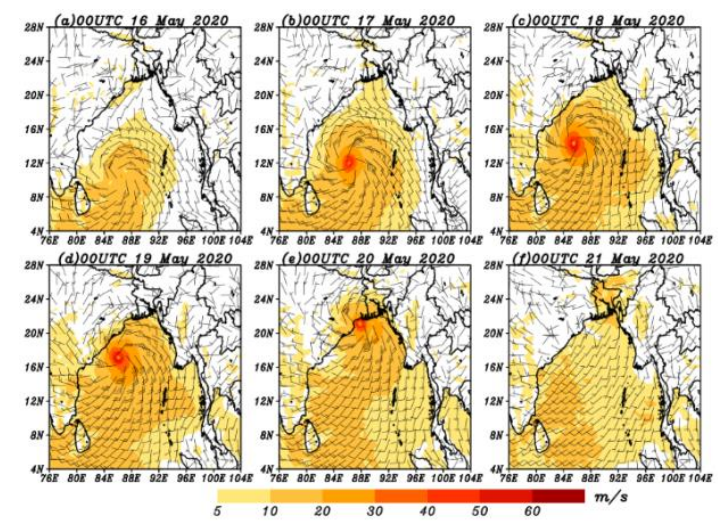

Figure 2: Model Simulated 10m Height Wind Flow Valid for 0000 UTC of (a) 16 May 2020, (b) 17 May 2020, (c) 18 May 2020, (d) 19 May 2020, (e) 20 May 2020 and (f) 21 May 2020

Figure 2 shows the model simulated $10 \mathrm{~m}$ height wind flow pattern valid for 0000 UTC of 16-21 May 2020 based on initial condition at 0000 UTC 16 May 2020. A well-organized cyclonic circulation with strong winds encircling the centre was found prominent in the in the model simulate $10 \mathrm{~m}$ height wind fields. The maximum wind speed captured by the model was about $243 \mathrm{kmph}$, which was very near to the observed value that was $241 \mathrm{kmph}$.
Maximum surface wind (MSW in kmph) and Mean sea level pressure (MSLP in $\mathrm{hPa}$ ) are the most important parameters characterizing the intensity of TCs. It directly affects the areas with its devastating actions. Besides, the storm surges are generated by the combined effect of pressure drop of the cyclone and the frictional force of the winds on the water of the sea surface. The space-based satellite technology is doing a great job in filling this gap of observation with estimates of MSW and other important parameters quite accurately. The intensity of Suc Amphan is analyzed from the time series of the observed, and 120 hours model simulates MSLP and MSW initialized at 0000UTC 16 May 2020, shown in Figure 3. The model simulated the central sea level pressure reasonably well. The predicted track of the tropical cyclone was drawn based on the model derived pressure chart and compared with the observed one. Also, the model simulated MSLP was more or less similar in pattern but it fairly underestimates the observed one. The lowest sea level pressure in model simulation $(905 \mathrm{hPa})$ was observed at 1800 UTC of 18 May 2020, which is very close to the observation $(920 \mathrm{hPa})$. The observed central pressure exhibits a sharp fall of the pressure since 17 May, 2020 indicating rapid development of Amphan, while the model shows rather a flattened pressure drop. Figure 3(b) shows the model simulated MSW speed overestimates the observed wind speed in most of the days. According to the figure, the model estimated maximum wind at $243 \mathrm{kph}$, whereas the observed maximum wind was closer to $241 \mathrm{kph}$. Therefore, the model can predict MSLP and MSW reasonably well throughout the 120 hours forecast duration.
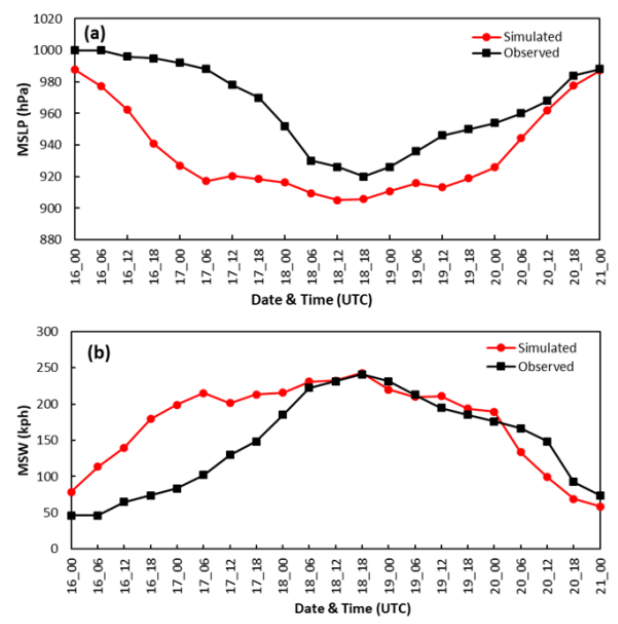

Figure 3: Time Series of Model Simulates and Observed (a) Mean Sea Level Pressure (mslp) and (b) Maximum Surface Winds (kmph) 
As per model simulation, the SuC Amphan upgraded to category 5 equivalent cyclones i.e., Super Cyclone valid at 12:00 UTC of 18 May 2020.

The model simulated lowest central pressure and highest maximum sustained wind were $905 \mathrm{hPa}$ and $243 \mathrm{kph}$ at 12:00 UTC of 18 May 2020 which were $920 \mathrm{hPa}$ and $241 \mathrm{kph}$ as observed.

\section{Vertical Profile of Temperature}

Temperature over both the Bay and land is an important parameter to develop and maintain the cyclonic activities. Figure 4 shows the model simulated vertical profile of temperature anomaly along latitude passing through the cyclone centre valid for 0000 UTC of (a) 16 May 2020, (b) 17 May 2020, (c) 18 May 2020, (d) 19 May 2020, (e) 20 May 2020. According to the Figure 4, the warm core of tropical cyclone has already started to develop on 16 May 2020. On 17 May 2020, this core of positive anomaly of temperature has further intensified in the form of a vertical tower reaching above $100 \mathrm{mb}$ level with a bell shape at the top. On 18 May the worm core intensified further, and the radius of the core widened, and temperature anomaly of $5^{\circ} \mathrm{C}$ was reached at 700 $100 \mathrm{mb}$. It is to mention that Amphan reached its maximum development with MSW of $243 \mathrm{kph}$ at this time. The warming of the cyclone core is caused by latent heat released through condensation from strong convections in the cyclone. Hence, the warming core is an indicator of the intensity of the tropical cyclone. The warm core is extended laterally to distribute its energy away from the cyclone, which might be an indicator for its weakening.

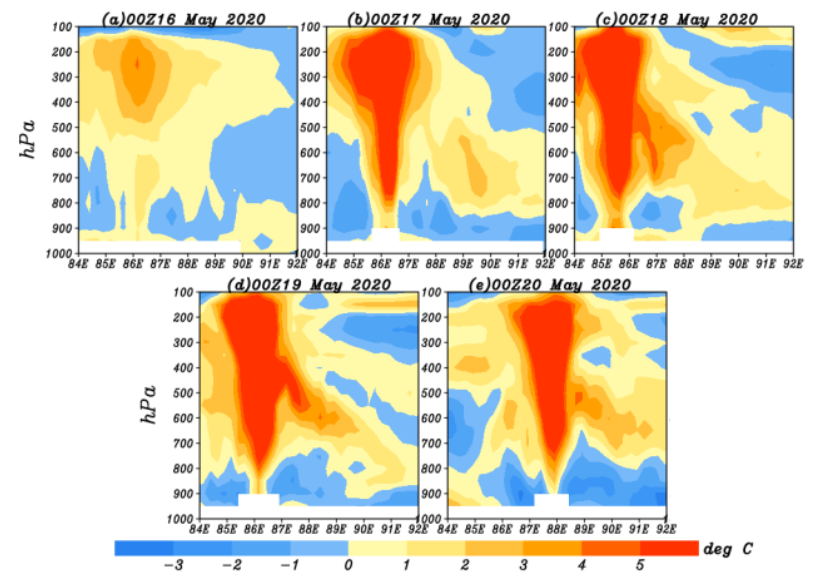

Figure 4: Mode Simulated Vertical Profile of Temperature Anomaly Valid at 0000 UTC (a) 16 May 2020, (b) 17 May 2020, (c) 18 May 2020, (d) 19 May 2020 and (e) 20 May 2020

\section{Vertical Profile of Relative Humidity}

Model simulated vertical profile of relative humidity along latitude and across the longitudes 80$100^{\circ} \mathrm{E}$ passing through the cyclone centre valid for 0000 UTC of (a) 16 May 2020, (b) 17 May 2020, (c) 18 May 2020, (d) 19 May 2020, and (e) 20 May 2020 is shown in Figure 5. It is found that the high value of relative humidity was observed along a narrow vertical zone, which extends up to $300 \mathrm{mb}$ level of the atmosphere. A zone of very high humidity of the order of $90-100 \%$ was observed over vertically extended narrow column from the boundary layer up to $300 \mathrm{mb}$ level.

\section{Precipitation Pattern}

The spatial distribution of model simulated 24-hrs accumulated rainfall of (a) 16 May 2020, (b) 17 May 2020, (c) 18 May 2020, (d) 19 May 2020, (e) 20 May 2020 and (f) 21 May 2020 is shown in Figure 6. The 24-hrs accumulated rainfall of each day is calculated for the duration from 0000 UTC of that day to 0000 UTC of following day. The figure depicts that the heavy rainfall was concentrated around the centre (red areas) of SuC Amphan. The typical spiral shapes are also maintained in the field of 24-hour rainfall. The red zone of heavy rainfall was found to follow the track during the landfall time. The rain band is found to narrow down further after the landfall [Figure 6 (f)].

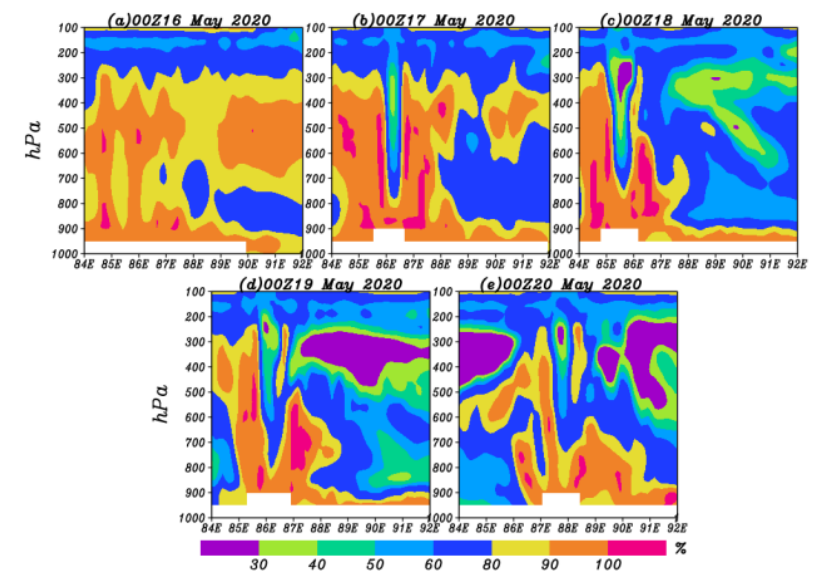

Figure 5: Model Simulated Vertical Profile of Relative Humidity Valid for 0000 UTC of (a) 16 May 2020, (b) 17 May 2020, (c) 18 May 2020, (d) 19 May 2020, and (e) 20 May 2020 


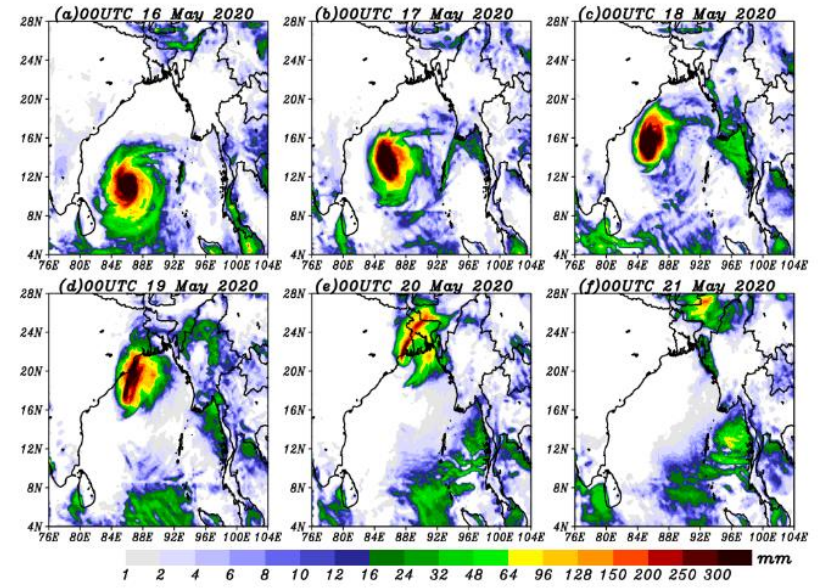

Figure 6: Model Simulated 24-hrs Accumulated Rainfall of (a) 16 May 2020, (b) 17 May 2020, (c) 18 May 2020, (d) 19 May 2020, (e) 20 May 2020 and (f) 21 May 2020

\section{Low Level Vorticity}

Low level relative vorticity is another important parameter for understanding dynamics of the tropical cyclones. Figure 7 shows the model simulated low level vorticity valid for 0000 UTC $16-21$ May of 2020. The figure exhibits that the SuC Amphan had very strong low-level vorticity at all stages including formation and dissipation.

The model simulated highest vorticity was $260 \times 10^{-5} \mathrm{~s}^{-1}$ at the core. The core area of high vorticity was found to expand with the increase of the intensity (red areas). The spiral banding characteristics around the core areas are clearly represented in the distribution of relative vorticity field.

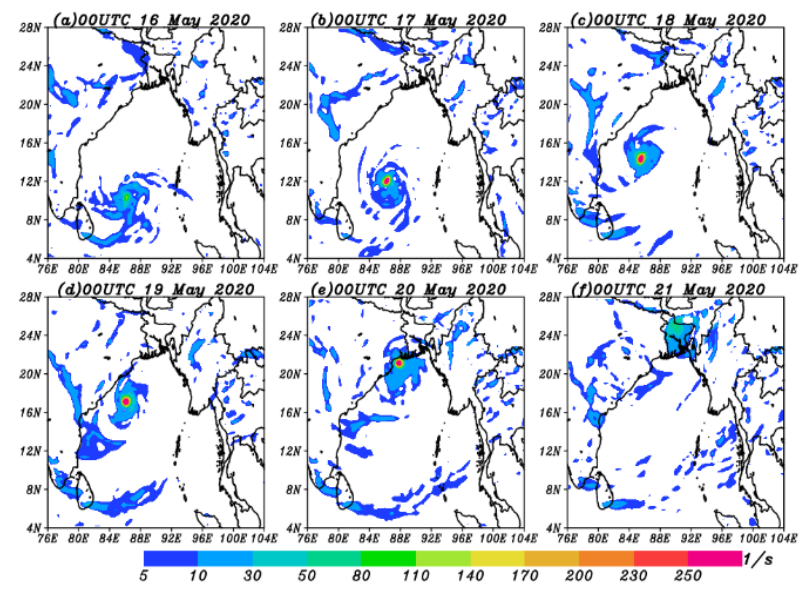

Figure 7: Model Simulates Low Level Relative Vorticity $\left(\sim 10^{-5} \mathrm{~s}^{-1}\right)$ Valid for 0000 UTC of (a) 16 May 2020, (b) 17 May 2020, (c) 18 May 2020, (d) 19 May 2020, (e) 20 May 2020 and (f) 21 May 2020

\section{Track Prediction of SuC}

The model predicted 120 hours track of SuC Amphan along with the best track of IMD are shown on Figure 8. The simulated 120 hours track of SuC Amphan is quite close to the best track throughout its path till landfall. There is on initial position error of the simulated track, although it is followed by the observed track with small deviation. However, there are some deviations of the predicted track from the observed before the landfall.

\section{Intensity and Track Errors Prediction}

The statistical distribution of error of model simulated parameters like track positions, MSLP and MSW can be analyzed for numerical predictions. The Mean Error (ME) and Standard Deviation (SD) are computed for Track position, mean sea level pressure and maximum surface wind which are presented in Table 1. In this analysis, the errors in the model simulated track are calculated using best track data of IMD as a reference.

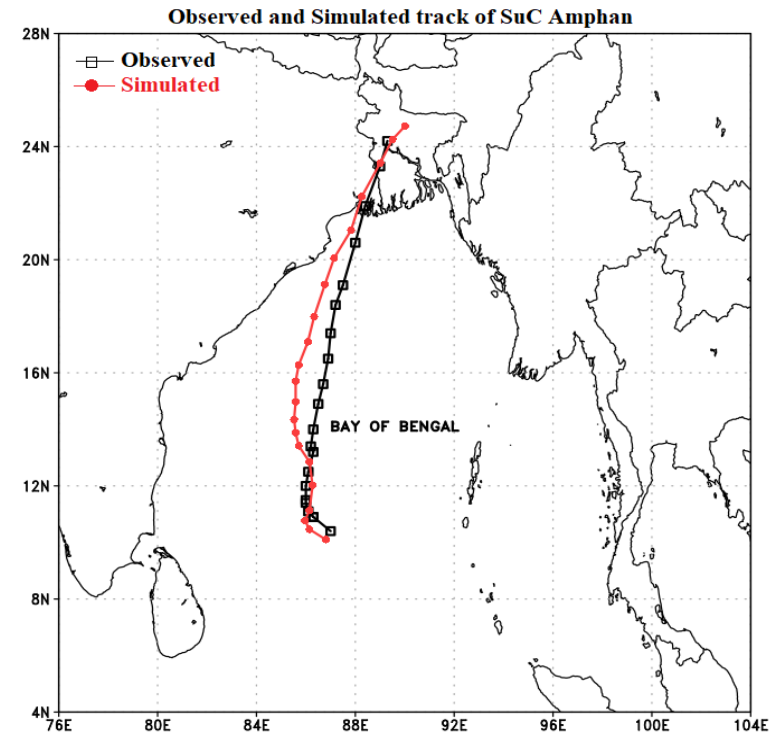

Figure 8: Comparison of Model Simulated Forecast Track (based on 0000 UTC of 16 May) With the Observed Track of IMD Best Track

Table 1. Mean Error (ME) and Standard Deviation (SD) of Model Simulated Track Position Error, MSLP and MSW of SuC Amphan

\begin{tabular}{|l|l|l|l|l|l|l|}
\hline $\begin{array}{l}\text { Forecast } \\
\text { period } \\
\text { (hours) }\end{array}$ & \multicolumn{2}{|l|}{$\begin{array}{l}\text { Track position } \\
\text { error } \\
(\mathrm{km})\end{array}$} & \multicolumn{2}{l|}{$\begin{array}{l}\text { Error in } \\
\text { MSLP (hPa) }\end{array}$} & $\begin{array}{l}\text { Error in MSW } \\
(\mathrm{kph})\end{array}$ \\
\cline { 2 - 7 } & $\mathrm{ME}$ & $\mathrm{SD}$ & $\mathrm{ME}$ & $\mathrm{SD}$ & $\mathrm{ME}$ & $\mathrm{SD}$ \\
\hline 120 & 139.6 & 67.3 & 29.3 & 61.2 & -28.2 & 47.3 \\
\hline
\end{tabular}


The Mean Error (ME) denotes the average of error at a given forecast time and the Standard Deviation (SD) denotes the error distribution around the mean error.

The ME value for MSLP of the selected SuC is positive (i.e., 29.3), suggesting that the model underestimates the mean sea level pressure as compared with the observation. The ME value for MSW of the selected SuC Amphan is negative (i.e. 28.2), indicating that the model overestimates the stronger winds as compared with observation.

Analyzing the ME value, it is found that the intensity of MSLP and MSW is well simulated by the model.

The ME for track position is $139.6 \mathrm{~km}$ at every 06 hours interval and error in initial vortex position is found $39.4 \mathrm{~km}$ which is comparatively small.

For better track prediction, reduction of error in initial position of the cyclonic vortex is necessary (Holland, 1984). It is clearly specified that there is a significant improvement in track prediction from the beginning due to small error in initial position. The movement of the SuC Amphan was faster and the cyclone made landfall at 7-8 hours before the actual landfall with $167.4 \mathrm{~km}$ position error.

\section{CONCLUSION}

Based on the results derived from model simulation and subsequent discussion made in the previous section, the following concluding remarks can be made:

The model simulated maximum sustained wind speed overestimates the observed wind speed in most of the days up to 0000 of 20 May except for 18 May 0000 to 19 May 0000 UTC, when the observed speed was $241 \mathrm{kph}$ while model simulated wind speed was $243 \mathrm{kph}$, the latter showing an underestimation. Model simulated the winds at $10 \mathrm{~m}$ height is reasonably well.

The model simulated sea level pressure is more or less similar in pattern but it is largely underestimated over the observed one. The lowest sea level pressure in model simulation $(905 \mathrm{hPa})$ was observes at 1800 UTC on 18 May which is very close to the observation $(916 \mathrm{hPa})$. The observed central pressure exhibits a sharp fall of the pressure since 17 May indicating rapid development of the system, while the model shows rather a flattened pressure drop.
From the vertical profile of relative humidity the high value of relative humidity was observed along a narrow vertical zone, which extends up to $300 \mathrm{mb}$ level of the atmosphere. A zone of very high humidity of the order of $90-100 \%$ is observed over vertically extended narrow column from the boundary layer up to $300 \mathrm{mb}$ level. The vertical profile of temperature positive anomaly has intensified in the form of vertical tower and reaching above $100 \mathrm{mb}$ level with bell shape at the top. The warming of the cyclone core is caused by latent heat released through condensations from strong convections in the cyclone. The warming core of the cyclone is an indicator of the $\mathrm{SuC}$ Amphan. The warm core is extended laterally to distribute its energy away from the cyclone, which might be an indicator for its weakening.

The prediction of heavy rainfall was concentrated around the centre of SuC Amphan. The typical spiral shapes are also maintained in the field of 24 hours rainfall. The heavy rainfall was found to follow the track during the landfall time. The rain band was found to narrow down further after the landfall.

As observed from the above experiment, the low level vorticity simulated well by the model and hence could predict the track well. The core area of high vorticity was found to expand with the increase of the intensity.

The model simulated 120 hours forecast has better predicted the intensity of the SuC Amphan in respect of both MSLP and MSW. It is also shown that, the landfall points of SuC Amphan are very close to the observed. However, there are some small deviations of the predicted track from observed before the landfall.

ACKNOWLEDGEMENTS: The authors would like to thank NCAR and NCEP of USA for providing the data for initial and lateral boundary condition. The authors would also like to thank IMD for providing observed best track, intensity and wind speed data. Thanks are due to the Department of Meteorology, University of Dhaka for providing the continuous support and facility to carry out this study.

\section{REFERENCES}

Bhaskar, R.D.V. and Hari P.D. (2006). Numerical prediction of the Odisha super Tropical Cyclone (2006) sensitivity to the parameterization of convection, boundary layer and explicit moisture processes. Mausam, 57: 61-78.

Dudhia, J. (1989). Numerical study of convection observed during the Winter Monsoon Experiment 
using a mesoscale two-dimensional model; J. Atmos. Sci., 46: 3077-3107.

Holland, G. J. (1984). Tropical cyclone motion: A comparison of theory and observations. J. Atmos. Sci., 41:68-75.

Hong, S.Y. and Lim, J. (2006). The WRF SingleMoment 6-Class Microphysics Scheme (WSM6); $J$. Korean Meteor. Soc., 42: 129-151.

Hong, Y.S., Noh, J.Y. and Dudhia. J. (2006). A new vertical diffusion package with an explicit treatment of entrainment process; Mon. Weather Rev., 134: 23182341.

Kain, J.S. Fritsch, J.M. (1993). Convective parameterization for mesoscale models: the KainFritsch scheme. In: KA Emanuel, DJ Raymond (eds) The representation of cumulus convection in numerical models. American Meteorological Society, USA, p 246.

McBride, J.L. and Fraedrich, K. (1995). CISK: A theory for the response of tropical convective complexes to variations in sea surface temperature. Quarterly Journal of the Royal Meteorological Society, 121(524): 783-796.

Mlawer, E.J., Taubman, S.J., Brown, P.D., Iacono, M.J. and Clough, S.A. (1997). Radiative transfer for inhomogeneous atmospheres: RRTM, a validated correlated-k model for the longwave; J. Geophys. Res., 102D 16: 663-682.

Mohanty, U.C., Osuri, K.K., Routray, A., Mohapatra, M. and Pattanayak, S. (2010). Simulation of Bay of Bengal tropical cyclones with WRF model: Impact of initial and boundary conditions. Marine Geodesy, 33: 294-314.

Mohanty, U.C, Mandal, M. and Raman S. (2004). Simulation of Odisha super-Tropical Cyclone (1999) using PSU/NCAR mesoscale model. Natural Hazards, 31: 373-390.

Mohapatra, M, Nayak, D.P, Sharma, R.P. and Bandyopadhyay, B.K. (2013a). Evaluation of official tropical cyclone track forecast over north Indian Ocean issued by India Meteorological Department. Journal of Earth System Science, 122: 433-451, doi:10.1007/s12040-013-0291-1.

Mohapatra, M, Bandyopadhyay, B.K. and Nayak, D.P. (2013b). Evaluation of operational tropical cyclone intensity forecasts over north Indian Ocean issued by India Meteorological Department. Natural Hazards, 68: 589-601, doi:10.1007/s11069-013-0624-z.

Mohapatra, M, Nayak, D.P, Sharma, M, Sharma, R.P. and Bandyopadhyay, B.K. (2015). Evaluation of official tropical cyclone landfall forecast issued by India Meteorological Department. Journal of Earth System Science, 124: 861-874, doi:10.1007/s12040015-0581-x.

Neumann, C. J. (1993). Global Overview, Chapter 1 Global Guide to Tropical Cyclone Forecasting, WMO. $\mathrm{TC},(560)$.

Osuri, K.K, Mohanty, U.C, Routray, A, Kulkarni, M.A. and Mohapatra, M. (2012). Customization of WRFARW Model with physical parametrization schemes for the simulation of Tropical Cyclones over the North Indian Ocean. Natural Hazards, 63: 1337-1359, doi:10.1007/s11069- 011-9862-0

Osuri, K.K, Mohanty, U.C, Routray, A. and Mohapatra, M. (2011). The impact of satellite-derived wind data assimilation on track, intensity and structure of Tropical Cyclones over the North Indian Ocean. International Journal of Remote Sensing, 2011: 1-26.

Osuri, K.K, Mohanty, U.C, Routray, A, Mohapatra, M. and Dev, N. (2014). Real-Time track prediction of tropical cyclones over the North Indian Ocean in the ARW model, Journal Of Applied Meteorology and Climatology, 52, doi:10.1175/JAMC-D-12-0313.1

Routray, A, Mohanty, U.C, Rizvi, S.R.H, Niyogi, D, Osuri, K.K. and Pradhan, D. (2010). Impact of Doppler weather radar data on simulation of Indian monsoon depressions. Quarterly Journal of the Royal Meteorological Society, 136: 1836-1850.

Skamarock, W.C., Klemp, J.B., Dudhia, J., Gill, D.O., Barker, D.M., Duda, M.G., Huang, X., Wang, W. and Powers, J.G. (2008). A Description of the Advanced Research WRF Version 3; NCAR Tech. Note (NCAR/TN-475+STR); National Centre for Atmospheric Research: Boulder, CO, USA, p. 125.

Srinivas, C.V, Venkatesan, R, Vesubabu, V. and Nagaraju, C. (2010). Impact of assimilation of conventional and satellite meteorological observations on the numerical simulation of a Bay of Bengal Tropical Cyclone of Nov 2008 near Tamilnadu using WRF model. Meteorology and Atmospheric Physics, 110: $19-44$. 
